\title{
ADHD, BEHAVIORAL AND DEVLOPMENTAL PROBLSMS IN CHILDREN
}

\author{
M. Kherkheulidze; N. Kavlashvili, E.Kandelaki, \\ State Medical University, Tbilisi, Georgia
}

\section{AIM}

The aim of the study was assessment of risk-factors and age correlated behavioral disorders in children.

\section{METHOD}

Study was conducted at lashvili Children's Central Hospital, in frame of Children's mental health state program. We evaluated children with behavioral disorders, attention deficiency and learning disabilities. Diagnosis was done by a multidisciplinary team (pediatric psychiatrist, child neurologist, pediatrician and psychologist) using different assessment tools. 342 patients aged 2-18 years were evaluated.

\section{RESULTS}

ADHD was diagnosed in $14,3 \%$, speech disorders $14,6 \%$, ASD - $12,8 \%$, learning problems $9 \%$, behavioral problems $14,3 \%$. In early childhood years isolated speech disorders and Autistic Spectrum Disorders is relatively high, while in elder children $(>6$ years) main problems are ADHD, behavioral and emotional problems and learning disability.

\section{Distribution of problems}

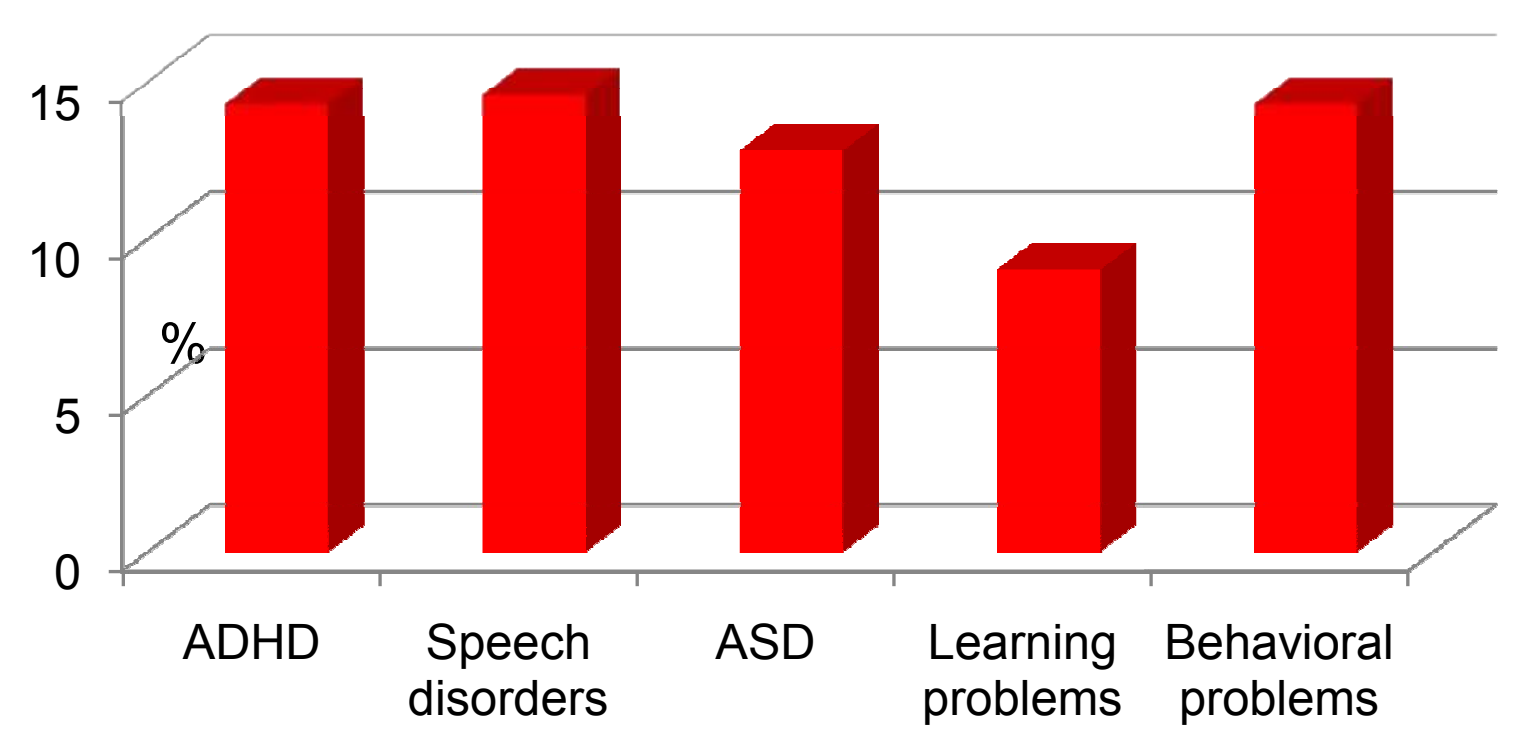

The ADHD as well as learning disabilities is twice more frequent in boys, than in girls $(p<0,05)$.
Mostly was seen isolated ADHD, in $28,5 \%$ ADHD was associated with antisocial behavior, in $4,1 \%$ with speech disorders. In children under 12 years ADHD is mainly associated with speech disorders, while after 12 with antisocial behavior $(p<0,05)$.

\section{Problems associated with ADHD}

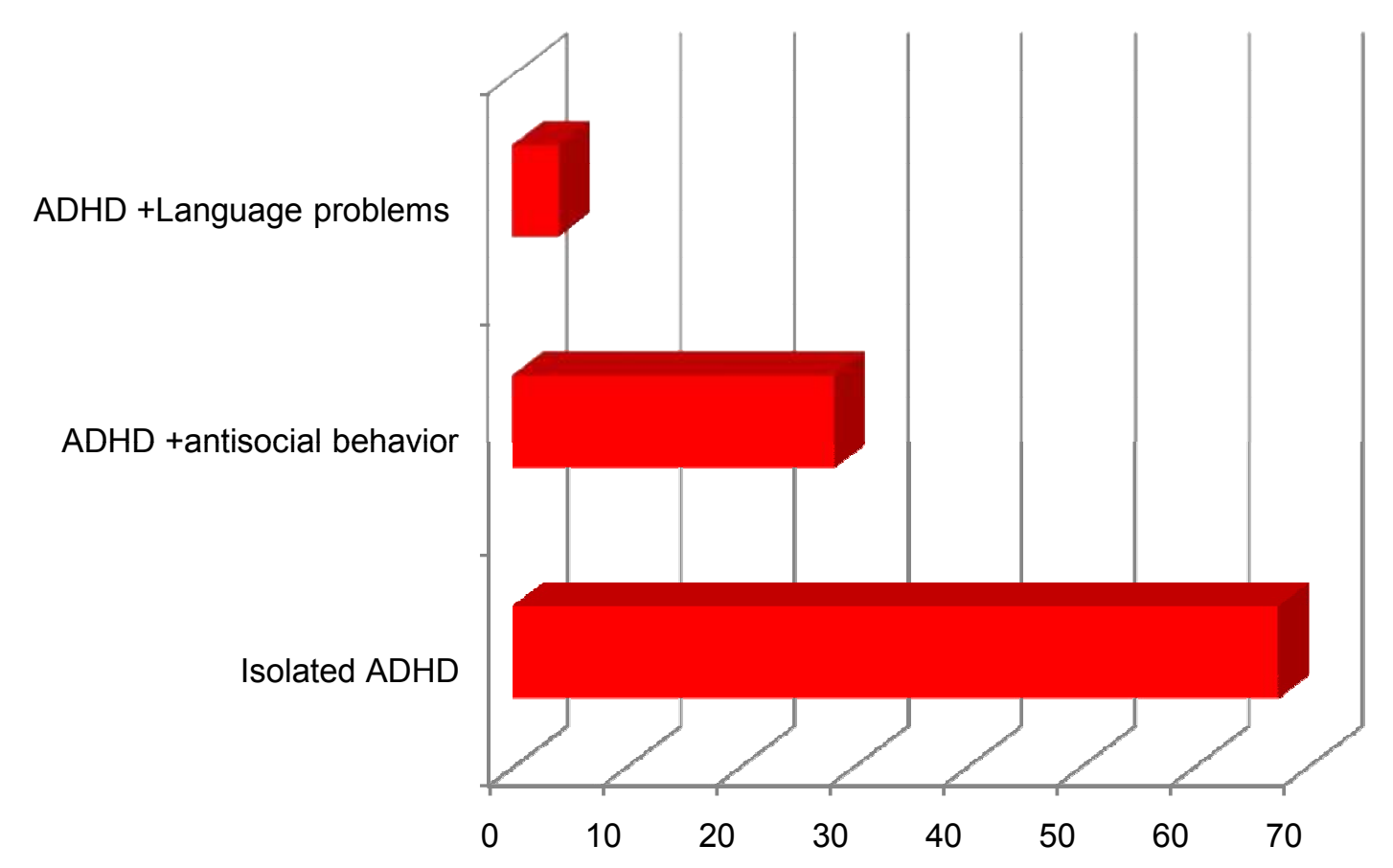

There is positive correlation with social riskfactors ( poverty, death in family, single parent) and ADHD, learning and emotional disorders

\section{Conclusion}

So in early years main development problems are speech disorders, ASD, Motor delay, while in elder (school age and adolescents) children behavioral and emotional disorders, ADHD and learning disorders are more frequent. ADHD is significantly higher in boys and after the puberty it is significantly associated with learning problems and antisocial behavior 